\title{
"Eu nem sabia que podia entrar aqui": promoçáo de cidadania cultural como experiência de ressignificação de identidade de jovens em conflito com a lei
}

\author{
Monica Villaça Gonçalves \\ Departamento de Terapia Ocupacional, Universidade Federal do Rio de Janeiro - UFRJ, \\ Rio de Janeiro, RJ, Brasil.
}

\begin{abstract}
Resumo: Este artigo tem como objetivo refletir sobre o uso da arte e da cultura como instrumentos da terapia ocupacional na promoção de cidadania e acesso aos direitos culturais e sociais de jovens em situação de vulnerabilidade social. Para tal, utiliza como metodologia o relato de experiência de uma ação envolvendo uma atividade relacionada ao campo da arte/cultura em uma unidade de cumprimento de medida socioeducativa de internação masculina. A experiência envolveu uma oficina de teatro, na qual os jovens participavam de todo o processo de construção das atividades, e uma visita a um grande teatro da cidade, em que foi garantido o direito à fruição estética. Observa-se que, ao garantir o direito à cultura, tanto na perspectiva de ator/produtor quanto de espectador, conseguimos ressignificar a identidade do jovem violento, em conflito com a lei, passando para o jovem cidadão, protagonista e sujeito de direitos, criando novas possibilidades de existir, estar e pertencer aos diferentes territórios que perpassam sua vida.
\end{abstract}

Palavras-chave: Atividades Humanas, Terapia Ocupacional, Cultura, Juventude, Medida Socioeducativa.

\section{"I didn't know I could get in here": cultural citizenship promotion as identity meaning experience of outlaw youth}

\begin{abstract}
This work aims to consider the use of art and culture as an Occupational Therapy instrument in citizenship promotion and access to cultural and social rights for young people in socially vulnerable situation. Therefore, it presents an experience report involving the use of activities related to art/culture in a male hospital socioeducational unit. The experiment involved a theater workshop in which the youth participating in the entire process of development activities, and a visit to great theater in town, in which it was guaranteed the right to aesthetic enjoyment. It is observed that, to guarantee the right to culture, both from the actor/producer and the viewer perspective, we can reframe the identity of the violent youth, in conflict with the law, moving to the young citizens, protagonist and subject of rights, creating new possibilities of existence, being and belonging to different territories that pervade your life.
\end{abstract}

Keywords: Human Activities, Occupational Therapy, Culture, Youth, Socioeducational Measures.

Autor para correspondência: Monica Villaça Gonçalves, Universidade Federal do Rio de Janeiro, Secretaria Acadêmica do Curso Terapia Ocupacional, Rua Prof. Rodolpho Paulo Rocco, s/n, Prédio do CCS, 3 Bloco K, Sala k, Primeiro Andar, Cidade Universitária, CEP: 21910-590, Rio de Janeiro, RJ, Brasil, e-mail: movillaca@hotmail.com.

Recebido em Maio 23, 2015; $1^{\text {a }}$ Revisão em Jul. 30, 2015; $2^{\text {a }}$ Revisão em Out. 12, 2015; Aceito em Nov. 17, 2015. 


\section{Introdução}

Em 2012 foi instituído no Brasil o Sistema Nacional de Atendimento Socioeducativo (SINASE), que regulamenta a execução das medidas socioeducativas destinadas à adolescentes que praticam atos infracionais. Tais medidas, previstas no Estatuto da Criança e do Adolescente - ECA (BRASIL, 1990), têm como objetivo não apenas o de responsabilizar o jovem pela prática do ato infracional, mas, sobretudo, promover a reconstruçấo de seu projeto de vida (BRASIL, 2006). Essa lei foi inspirada nos acordos internacionais sobre direitos humanos dos quais o Brasil é signatário, em especial na área dos direitos da criança e do adolescente.

Hoje, a discussão sobre a responsabilidade/ responsabilização de adolescentes pelos atos cometidos tem sido colocada em pauta nos espaços acadêmicos, políticos e na mídia, através principalmente dos meios de comunicação de massa, pois dissemina-se a falsa ideia de que jovens cometem mais crimes por estarem salvos/livres de qualquer forma de responsabilização pelos seus atos.

Entretanto, sabe-se que, mais que cometerem atos violentos, os jovens são as maiores vítimas deles. Em levantamento preliminar de 2013, a Secretaria de Direitos Humanos - SDH divulgou que os homicídios representam $46 \%$ de todas as causas de mortes de adolescentes brasileiros (BRASIL, 2013). $\mathrm{O}$ estudo revela ainda que ser do sexo masculino e negro aumenta as chances de o adolescente ser vítima de homicídio.

Além da violência física, os adolescentes também são a parcela da população que mais sofre com outra forma de violência, caracterizada pela privação de acesso aos seus direitos. Em 2013, por exemplo, dos 10,6 milhóes de jovens de 15 a 17 anos brasileiros, mais de 1,0 milhão não estudavam e nem trabalhavam; 584,2 mil só trabalhavam e náo estudavam; e, aproximadamente, 1,8 milhão conciliavam as atividades de estudo e trabalho (SILVA; OLIVEIRA, 2015).

Sabemos que os adolescentes, especialmente os pobres, moradores da periferia e já vítimas de violências de diferentes contextos, são sim responsabilizados pelos atos infracionais cometidos.

Segundo dados de 2012 da SDH, a porcentagem de adolescentes cumprindo medida socioeducativa no Brasil, em comparação com a população geral nessa faixa etária, é de apenas $0,10 \%$ nas medidas de restrição e privação de liberdade e de apenas $0,41 \%$ em medidas socioeducativas de prestaçáo de serviços à comunidade e liberdade assistida (BRASIL, 2013). Percebemos ser uma parcela bem pequena dessa populaçáo, se compararmos com os números de adolescentes vítimas. A maior parte dos adolescentes cumpre medida por roubo $(40,01 \%)$, seguido por tráfico de drogas $(23,46 \%)$ e homicídio (8,81\%). Uma publicação do Instituto de Pesquisa Econômica Aplicada - IPEA, de 2013, sobre o perfil desses jovens que cumprem medida socioeducativa de privação de liberdade, revela que $95 \%$ eram do sexo masculino e cerca de $60 \%$ tinham idade entre 16 e 18 anos. Como náo foram encontrados dados mais recentes sobre as características sociais desses jovens, as autoras utilizaram um levantamento do IPEA e do Ministério da Justiça (2003) apud Silva e Gueresi (2003), que mostram um perfil de exclusão social entre esses adolescentes: mais de $60 \%$ eram negros, $51 \%$ não frequentavam a escola, $49 \%$ não trabalhavam quando cometeram o delito e $66 \%$ viviam em famílias consideradas extremamente pobres.

Os princípios de brevidade e excepcionalidade da privaçáo de liberdade não têm sido garantidos a esses jovens. Ao contrário do que preconiza o Sinase, as medidas de internação são as mais indicadas, em detrimento da prestação de serviços comunitários e a liberdade assistida (BRASIL, 2010). A pesquisa "Responsabilidade e Garantias ao Adolescente Autor de Ato Infracional: uma proposta de revisão do ECA em seus 18 anos de vigência”, realizada pela Universidade Federal da Bahia, em parceria com o Ministério da Justiça, através da Secretaria de Assuntos Legislativos, aponta, inclusive, que a análise de processos de julgamento de jovens que cometeram atos infracionais

revelam posicionamentos ideológicos, valorativos, extrajurídicos que alheios ao mundo do direito se coadunam com as visóes do senso comum sobre a criminalidade em geral, e em particular sobre a delinquência na adolescência (MINAHIM, 2010, p. 11).

Apesar dessa realidade sobre os contextos sociais e de vulnerabilidade da juventude brasileira, e das estatísticas que apontam ser baixa a porcentagem de adolescentes que cometem atos infracionais, o debate sobre a responsabilização desses adolescentes por esses atos, ao ser pauta das agendas governamentais, é realizado com discursos permeados pelos interesses políticos e econômicos particulares, em que as políticas públicas ditas de "controle da criminalidade" muitas vezes se sobrepóem em detrimento da execução de projetos políticos voltados para o desenvolvimento pleno e fomentador do protagonismo juvenil.

Diante desse quadro, entendemos ser importante avaliar as experiências e os processos de trabalho que vêm sendo realizados nos serviços socioeducativos, já que é através dessas açôes que o Sinase se institui como lei e garante ao adolescente que a medida 
será aplicada tendo um caráter pedagógico e não punitivo, garantindo a esses adolescentes a defesa de seus direitos.

Este artigo tem como objetivo refletir sobre o uso da arte e da cultura como instrumento da terapia ocupacional na promoção de cidadania e acesso aos direitos culturais e sociais para jovens em situação de vulnerabilidade social em cumprimento de medida socioeducativa.

Para tal, utiliza como metodologia o relato de experiência de uma ação envolvendo atividades relacionadas ao campo da arte/cultura em uma unidade masculina de cumprimento de medida socioeducativa de privação de liberdade.

\section{Contextualização}

A unidade de internação em que ocorreu a experiência relatada, considerada referência na cidade onde se localiza, recebia cerca de 120 meninos, entre 12 e 19 anos (alguns ficavam após a completude da maioridade penal para finalização do cumprimento da medida), moradores de todo o Estado (capital e interior), com diferentes contextos na unidade. Alguns passavam pela primeira internação, outros já eram reincidentes; alguns mantinham contato próximo com a família, outros moravam em abrigos ou estavam em situação de rua; alguns apresentavam transtornos mentais ou uso abusivo de álcool e outras drogas. Poucos estavam na escola, e quando estavam apresentavam-se atrasados em relação ao previsto para sua idade. Em comum, tinham a experiência de viver em bairros pobres, onde o poder era exercido pelo tráfico de drogas, e viviam sob o estigma do jovem pobre e violento das favelas. Essas características assemelham-se aos dados apresentados por alguns levantamentos nacionais sobre o perfil dos jovens em cumprimento de medida socioeducativa, como já mostrado anteriormente.

$\mathrm{Na}$ experiência relatada, utilizamos como eixos norteadores os conceitos de cidadania cultural e protagonismo juvenil.

\section{Cidadania pode ser entendida como}

a participação dos indivíduos de uma comunidade em busca da igualdade em todos os campos da realidade humana, mediante a luta pela conquista e ampliação dos direitos civis, políticos e sociais, o que determina novos rumos para a vida da comunidade e para a própria participação (MARTIN, 2007, p. 84).

Cidadania, nessa perspectiva, implica a conquista de igualdade social, e indivíduo cidadão é aquele que participa da luta política e no desenvolvimento de açóes na busca dessa igualdade. Entretanto, sabemos que "as desigualdade sociais e situaçóes econômicas dos indivíduos afetam diretamente sua participação" (MARTIN, 2007, p. 84). No caso da população a que nos referimos nessa experiência, os jovens em cumprimento de medida socioeducativa, sabemos que o exercício de sua cidadania é uma realidade distante diante das condiçôes sociais em que vivem. Assim, para promover essa participação, é preciso investir em açôes que fomentem o desenvolvimento do protagonismo desses adolescentes. Protagonismo juvenil pode ser definido como a participação de jovens/adolescentes como personagens principais no enfrentamento de situaçóes reais de sua vida social (COSTA, 2001), e é fundamentado na pedagogia ativa. $\mathrm{O}$ conceito de protagonismo juvenil envolve um nível de participaçáo do jovem mais elevado do que a participação social. Nas atuaçóes para o protagonismo juvenil, as relaçóes são horizontalizadas, as decisóes e açóes são tomadas democraticamente e de forma conjunta, sempre colocando o jovem na posição central do projeto e das açôes, que tem em seus objetivos práticas voltadas para os benefícios de um coletivo (BORBA, 2007).

Trabalhando com açôes que promovam a cidadania de uma forma geral e o protagonismo juvenil, é possível pensar na promoção da cidadania cultural dessa população.

A cultura é considerada um dos direitos fundamentais do homem desde a Declaração Universal dos Direitos Humanos, de 1948. No Brasil, o conceito de cidadania cultural teve suas primeiras discussóes a partir das reflexóes da filósofa Marilena Chauí, que entende que o acesso à cultura é um direito de todo cidadáo, e que o Estado deve ser um agente das políticas culturais. Para essa autora, a discussão sobre as políticas culturais deve ser focada

na relevância da cultura no projeto de transformaçáo da sociedade, em uma perspectiva democrática e socialista. A cultura é apresentada como um campo que possibilita as transformaçóes sociais pelo significado de resistência que ela tem para as classes dominadas (FERNANDES, 2011. p. 179).

Nas palavras da própria autora, é preciso pensar no papel da cultura seja como fator de discriminação sócio-política, seja como instrumento de dominação ideológica, seja como forma de resistência das classes dominadas, seja, enfim, como forma de criação com potencial de emancipaçáo e de liberação histórica (CHAUÍ et al., 1985, p. 5). 
Cidadania cultural é então o direito à cultura, que é compreendido a partir dos seguintes aspectos:

direito de produzir cultura, seja pela apropriaçáo dos meios culturais existentes, seja pela invenção de novos signos culturais;

o direito de participar das decisóes quanto ao fazer cultural;

o direito de usufruir dos bens da cultura, mediante a criação de locais e condiçôes de acesso aos bens culturais para a população;

o direito de estar informado quanto aos serviços culturais e as possibilidades de dele participar ou usufruir;

o direito à formação cultural e artística pública e gratuita nas Escolas e Oficinas de Cultura do Município;

o direito à experimentação e à invenção do novo nas artes e nas humanidades;

o direito a espaços para reflexão, debate e crítica; o direito à informação e à comunicação (CHAUÍ, 1992, p. 15-16).

Takeiti (2014) afirma que as expressões culturais juvenis são importantes formas de sociabilidade e de expressão da realidade social em que vivem, desconhecidas de grande parte da população. As intervençóes estéticas e artísticas permitem maior visibilidades dessa realidade nos veículos de comunicação e representam forma de resistência desse jovens às "culturas prescritivas que lhes impóem" (TAKEITI, 2014, p. 176).

Garantir o protagonismo e o direito à cidadania cultural dessa população, não no sentido apenas do consumo de cultura, mas como uma forma de trabalho, criação e manifestação política, parece ser uma forma importante de trabalhar com os estigmas sofridos por esse grupo.

\section{Atividades e terapia ocupacional social}

A Terapia Ocupacional é um campo de conhecimento e intervençáo em saúde, educação e na esfera social, reunindo tecnologias orientadas para a emancipação e autonomia para as pessoas que, por razões ligadas a problemáticas específicas, apresentam dificuldades na inserção e participação na vida social. As intervençôes em Terapia Ocupacional dimensionam-se pelo uso da atividade [...] (FMUSP, 1997 apud WORLD...; ASSOCIAÇAO...; CENTRO..., 2003, p. 70).

Assim, entendemos a terapia ocupacional como a profissão que se debruça sobre a atividade humana, em suas diversas dimensóes, e que trabalha com estas atividades de forma a dar um sentido/significado para elas. Este é o elemento que diferencia a profissão das outras práticas. Utilizar atividades humanas não é exclusividade do terapeuta ocupacional, mas o como ela é usada é que diferencia a prática profissional.

Ressaltamos ainda que a atividade, instrumento básico da terapia ocupacional, está presente na vida do homem e transporta todas as relaçóes que envolvem o sujeito: está vinculada às relaçôes sociais, políticas e culturais deste; é determinada e determinante cultural e politicamente. Atuam como forma de dizer da condição humana, e ocorrem segundo as experiências culturais e de vida social do indivíduo (BARROS; LOPES; GALHEIGO, 2007b; LOPES et al., 2008). As atividades náo possuem nem significados fixos, nem significados únicos - elas sempre têm sentidos e significados múltiplos. São expressóes das identidades e participam de processos que formam identidades (BARROS, 2004; LOPES et al., 2008; grifo nosso).

As atividades na terapia ocupacional estão relacionadas a múltiplos fazeres e podem ser realizadas individualmente ou em grupo. São recursos importantes para a expressão de subjetividades individuais e coletivas, e devem ser utilizadas de forma a despertar capacidade de criação, potência para a açáo e mudanças nas formas normatizadoras e hierarquizadas de existir nos diversos contextos da vida (BARROS, 2004; LOPES et al., 2006; BARROS; LOPES; GALHEIGO, 2007b; LOPES et al., 2008). Além de recursos de intervenção, são também meios de aproximação com o indivíduo, grupo ou o coletivo com o qual se irá trabalhar.

A Terapia Ocupacional Social surge na década de 1970, em um contexto de redemocratização do país, disparado por movimentos populares, quando os profissionais que trabalhavam em instituiçóes como as FEBEMs - Fundação de Bem-Estar do Menor, os asilos, os presídios e em programas comunitários para crianças e adolescentes de baixa renda passam a fazer críticas às práticas e fundamentos utilizados até então, reconhecendo existir uma atuação diferente das já conhecidas (reabilitação física e saúde mental), porém ainda não entendida como um campo com fundamentaçáo e metodologias de ação próprias. Inicia-se, na construção desse campo, uma redefinição 
de objetivos e instrumentos da intervenção através da renúncia à adoção de pressupostos orientados pelo eixo saúde-doença e do descentramento do saber técnico para a ideia de saberes plurais diante de problemas e questôes sociais (BARROS; GHIRARDI; LOPES, 2002; GALHEIGO, 2003b).

Hoje, a Terapia Ocupacional Social é reconhecida como uma das especificidades da profissáo ${ }^{1}$.

Nesse campo entende-se a atividade como um instrumento de emancipação. A atividade tem uma dimensão sociopolítica, cultural e afetiva, e pessoas, grupos e comunidade são então processos relacionais e políticos. Assim, a atividade "entendida como direito social é aquela que, coletivamente, significa e produz significado social" (COSTA, 2012, p. 44).

Nessa perspectiva, o foco das ações deixa de ser o indivíduo e passa a ser centrada nos coletivos e nas relaçôes estabelecidas nestes. Consideramos, portanto, que há um "descentramento" das açôes de um único sujeito para o coletivo, entendendo-o como parte da vida da pessoa, com suas particularidades e uma cultura da qual este indivíduo não pode ser separado (BARROS; LOPES; GALHEIGO, 2007a). Reis (2008, p. 26) afirma que as abordagens da Terapia Ocupacional Social não se definem a partir das similaridades das características da população, e sim pelo grau de "distanciamento em que essa população se encontra do exercício de seus direitos fundamentais".

A cidadania passa a ser o eixo articulador das açôes do terapeuta ocupacional nesse campo. E, diante da discussão da cultura enquanto direito, e do entendimento da necessidade de se trabalhar para a efetivação do direito à cidadania cultural, podemos pensar que os recursos e tecnologias utilizadas pela Terapia Ocupacional Social podem ser promotores desse acesso.

O terapeuta ocupacional deve ter o papel de promover um espaço onde as dificuldades e contradiçôes vividas pelo sujeito possam ser trazidas para o fazer concreto, abrindo entâo a possibilidade de reconhecimento e enfrentamento de suas dificuldades cotidianas na busca por um enriquecimento de suas necessidades.

No caso de adolescentes institucionalizados, as atividades devem ser trabalhadas pelo profissional com o objetivo de: possibilitar que esses adolescentes sejam capazes de experimentar e ressignificar sua relação com o fazer; (re)estabelecer laços sociais; elaborar conflitos e formas alternativas à linguagem da violência; possibilitar o alcance dos desejos e necessidades do sujeito, bem como a ampliação de vivências e repertórios socioculturais para sua vida; ajudar o adolescente e elaborar projetos de vida e desconstruir discursos e identidades ocupacionais criminais (GALHEIGO, 2003a; MALFITANO, 2005; BARROS; LOPES; GALHEIGO, 2007b; SANTOS; FEDEGER, 2008).

É importante também, na atuação em uma instituição total ${ }^{2}$, que se trabalhe com a transiçấo para a liberdade, relacionando as atividades com o cotidiano do adolescente no seu território. Nessa perspectiva, é necessário também romper barreiras institucionais que levem à dinâmica de uma "instituiçấo total", onde os internados perdem sua autonomia, têm seus desejos, vontades e individualidades reprimidos e sofrem uma quebra de sua identidade, a partir de açóes como o corte de cabelo, a obrigatoriedade do uso de uniforme, os horários determinados para atividades. Evitar essa "mortificação do eu" (GOFFMAN, 1990) através de atividades que permitam a escolha, a (re)construção de uma identidade, o contato com o mundo externo e a construçáo de uma subjetividade única, singular, não "normatizada" aos padrôes institucionais é uma prática comum aos terapeutas ocupacionais que atuam nesses espaços.

São diversos os recursos sócio-ocupacionais que podemos utilizar com o objetivo de fomentação do protagonismo juvenil, ressignificação de identidades criativas e potentes, promoção do sentimento pertencimento social e territorial e facilitador do diálogo intercultural. Falamos de atividades artísticas, plásticas, música, fotografia, reconstrução de memória individual e coletiva, oficinas, grupos, rodas de conversa, jogos interativos, vídeos, intervençôes urbanas, entre diversas outras. É importante que a experimentaçáo com as atividades seja um espaço prazeroso de sociabilidade e trocas e que possa transcender para os contextos de vida desses jovens.

No caso da experiência relatada, o recurso utilizado foi o teatro. Boal $(1990,2009)$ afirma que o teatro é a experiência a partir da qual, ao ver-se em ação, o homem percebe-se e pode analisar a situaçáo em que se encontra. É ainda um espaço no qual pode se autodirigir durante a atividade. Assim, o teatro torna-se um potente elemento de produção cultural disparador e provocador de questionamento, além de ser uma atividade corporal e expressiva facilitadora do processo de subjetivação, conforme afirma Liberman (2002).

\section{4 "Eu nem sabia que podia entrar aqui": a experiência do teatro}

As unidades socioeducativas de internação têm como característica a privação de liberdade. Embora 
o Sinase tenha em seus princípios a "incompletude institucional", que significa, conforme previsto no art. 86 do ECA (BRASIL, 1990), que se deve utilizar ao máximo possível os serviços da comunidade e responsabilizar as políticas setoriais no atendimento aos adolescentes, no caso da medida de internaçáo nem sempre essa incompletude é real.

No espaço da unidade onde ocorreu a experiência, os adolescentes não podiam sair para nenhuma atividade, sendo dentro do espaço físico da unidade a escola, a assistência odontológica, médica e em saúde mental. Assim, o contato com a comunidade era restrito às visitas semanais que os familiares podiam realizar.

Pontualmente, alguns eventos externos aconteciam, mas era pequeno o número de meninos que participavam, por questôes de organização institucional.

Um dos eixos de atuação destacado pelo Sinase é o da "Cultura, esporte e lazer". As açôes desse eixo devem fazer parte de todas entidades e/ou programas que executam as diferentes medidas socioeducativas. Nesse eixo, temos a determinaçáo de que as açóes socioeducativas devem:

(2) propiciar o acesso a programação cultural, teatro, literatura, dança, música, arte, construção de espaços de oportunização da vivência de diferentes atividades culturais e artísticas, e também de favorecimento à qualificação artística do adolescente [...];

(5) assegurar no atendimento socioeducativo espaço a diferentes manifestações culturais do adolescente [...];

(8) garantir que atividades de esportivas, de lazer e culturais prevista do projeto pedagógico sejam efetivamente realizadas, assegurando assim que os espaços físicos destinados às práticas esportivas, de lazer e culturais sejam utilizados pelos adolescentes [...] (BRASIL, 2006, p. 60).

Buscando garantir que esses princípios sejam efetivados, nesta instituição, além das atividades esportivas, semanalmente os adolescentes podiam participar de uma oficina de teatro, coordenada por um professor/ator. Nestas oficinas, estavam os jovens que manifestavam interesse na atividade, alguns por demanda espontânea ao ouvirem os relatos de outros participantes, outros por recomendação da equipe que os atendia, que tinha o papel de apresentar as atividades da unidade e indicar a participação em algumas delas, de acordo com os desejos do adolescente. $\mathrm{Na}$ época da experiência relatada, cerca de 15 adolescentes participavam da oficina.

Justa e Holanda (2012), em uma experiência realizada com jovens em situação de vulnerabilidade social, colocam o teatro como um instrumento facilitador na construção da subjetividade; como promotor da percepção da potência de transformação social e participação sociocultural; e como recurso de linguagem e produção artística usada pela terapia ocupacional. Dessa forma, entendemos ser um potente recurso a ser utilizado com os jovens em cumprimento de medida socioeducativa.

Desta atividade, além do professor, faziam parte também uma terapeuta ocupacional e uma pedagoga, nem sempre da oficina em si, mas de discussóes e proposições coletivas de desejos despertados nos adolescentes após a experiência nas oficinas. $\mathrm{Na}$ atividade, os adolescentes participavam de todo o processo de criação, iniciando pela escolha da temática, passando pela definição de personagens, cenário, criação do roteiro da história e a atuação. Retomando os pensamentos de Boal (2002), Justa e Holanda (2012, p. 18) afirmam que o teatro possibilita que o homem observe a si mesmo em ação, adquira autoconhecimento e "faz com que cada um se aproprie da experiência que originalmente é sua".

Grande parte das peças encenadas abordavam temáticas como violência, uso de drogas, cometimento de atos infracionais, relacionamentos amorosos conflituosos. Tinham em comum sempre um desfecho de superação da problemática encenada, muitas vezes pelo cunho religioso. Sabemos que na realidade de jovens pobres, sem acesso aos direitos sociais básicos e vivendo em espaços onde o Estado mostra-se ausente, sendo então "substituído" pelo poder paralelo do tráfico ou das milícias, essas temáticas perpassam o cotidiano e fazem parte das vivências do dia a dia.

Fefferman (2006) e Zaluar (2004) apontam que a população pobre é vítima de uma violência que denominamos estrutural ${ }^{3}$, perpetrada pelo Estado, e que vem oprimindo grande parte da população, que por esse motivo se encontra em situação de vulnerabilidade social. As situaçóes de desrespeito e privaçóes pelas quais passam em seus territórios sáo propulsoras para a entrada e o crescimento de setores ilegais e criminosos, como é o caso do tráfico de drogas ilícitas por exemplo. São nesses lugares que o tráfico torna-se visível e exerce um grande poder na populaçáo, uma vez que o Estado se mostra omisso e violento ${ }^{4}$. Nesses espaços existe um novo tipo contrato social, que pode ser definido como "qualquer acordo entre indivíduos independentes com respeito a disposiçóes institucionais básicas que 
deverão determinar seus relacionamentos sociais e políticos" (OUTHWAITE; BOTTOMORE, 1996, p. 137). Este conceito busca explicar e justificar os direitos ou obrigaçóes que os indivíduos têm uns para os outros em uma sociedade e/ou Estado. O contrato, nesse caso, é com o poder do tráfico.

No tráfico, esse contrato social declara que o poder está no mais forte. Para a sua manutenção, institui um grupo de regras que propiciam o seu funcionamento. Todos os envolvidos estão cientes dessas regras e de suas obrigaçóes e, principalmente, das consequências caso não as cumpram.

Entre os traficantes, as relaçóes de poder são conhecidas e legitimadas, tendo como referência os mesmos ícones da sociedade burguesa, o poder do capital (FEFFERMAN, 2006, p. 250).

O chefe do tráfico e seus "parceiros" comandam todas as instâncias da comunidade. Atuam como o "Estado" ausente no espaço, designam as leis, os direitos e deveres, responsabilizam-se pelo cumprimento destas e pela garantia da ordem na comunidade. $\mathrm{O}$ crescimento do tráfico leva ainda o afastamento das pessoas das associaçóes dos bairros em prol das causas coletivas, o que possibilita apropriaçáo desses espaços para a participação dos traficantes na política local. Estes passam a exercer papel de segurança e a financiar projetos comunitários como praças esportivas (ZALUAR, 2004). Entretanto, é importante entender que a presença do poder exercido pelo tráfico também é violento, e apesar de "suprir" algumas necessidades básicas que não foram garantidas pelo Estado (como alimentação, moradia, escola e espaços de lazer, por exemplo), ainda trabalham de forma a manter a desigualdade social dentro das favelas.

Os moradores têm uma representação ambígua dos traficantes. De um lado, têm medo, pois os consideram perigosos pelas atitudes violentas que veem; de outro, consideram-nos como protetores. Diante disso, o que impera é a lei do silêncio. $\mathrm{O}$ medo é um instrumento de dominação (FEFFERMAN, 2006, p. 279).

Através da representação dessas vivências nas oficinas de teatro, podemos possibilitar que esses jovens percebam-se mais responsáveis por sua realidade, assim como mais capazes de transformá-las. A atividade expressiva permite que o sujeito encontre e dramatize possibilidades de enfrentamento de sua realidade social.

Sempre que possível, as peças eram apresentadas dentro da Unidade, para profissionais, outros adolescentes e familiares. Algumas vezes, essas apresentaçóes aconteciam durante a semana, o que acabava dificultando a presença dos familiares; em outros momentos se dava em eventos, como festa de dia das mães ou Natal, por exemplo. Nesses eventos, era possível que os jovens partilhassem sua construção com seus familiares, que em muitos momentos se emocionavam pela identificação da realidade representada nos palcos.

Após alguns meses nessa parceria, com o envolvimento maior de um grupo de adolescentes na oficina, apareceu a demanda de conhecer um espaço de teatro "de verdade". Partindo desse desejo, foi organizada uma visita guiada ao Theatro Municipal do Rio de Janeiro, localizado no centro da cidade. Nessa visita, os visitantes dispóem um guia, que conta toda a história da construçáo e reforma do teatro, atores e peças apresentadas, arquitetura e decoração.

$\mathrm{Na}$ visita, foram cerca de 15 adolescentes que participavam da oficina, o professor, a terapeuta ocupacional, a pedagoga e alguns agentes socioeducativos. Apesar da solicitação de que fossem disponibilizadas roupas sem o logo do departamento para o passeio, esta náo foi concedida, portanto os adolescentes foram ao local vestindo o uniforme da instituição.

Durante o percurso, realizado em uma van, os meninos olhavam pela janela de forma nostálgica, observando as belezas da cidade e apontando os bairros que conheciam, embora todos fossem de regiôes distantes ao caminho feito: "dá saudade da vida fora da 'prisão'[...]".

Percebemos que, diferentemente do que muitas vezes é divulgado pelos meios de comunicação em massa, os adolescentes sentiam-se sim "pagando pelo que fizeram", diferentemente da crença popular de que o número de adolescentes cometendo atos infracionais cresce devido à falta de "punição". Todos eles sempre se referiam à unidade como "prisão", por mais que frequentemente fosse discutido entre eles o caráter socioeducativo da medida e seus objetivos.

Chegando ao teatro, os agentes socioeducativos desceram antes dos técnicos e dos adolescentes para verificar a segurança do local. Pudemos perceber o grande número de pessoas com olhares curiosos ao verem os adolescentes descendo com o uniforme, cabelos raspados, cabeça baixa e em fila. Porém, não pareceram se importar muito, logo se comportando como meninos, brincando e admirando a parte externa do local.

A guia que nos recebeu mostrou-se muito receptiva com os adolescentes e fez sua apresentaçáo em uma linguagem informal, aproximando-se assim do universo juvenil. Os meninos, no começo tímidos, 
logo se mostraram à vontade para fazer perguntas, comentários e brincadeiras. Questionaram quem eram "as mulheres pintadas nas paredes" (deusas gregas representando as artes), quem "limpava um lugar tão grande" e "quem pagava a conta de luz". Ao entenderem que se tratava de um espaço público, no qual a manutenção era de responsabilidade do governo, não seguraram o comentário: "Então o governo tem muito dinheiro mesmo, porque a luz 'tá' muito cara". A esta frase, outro jovem complementa: "tem (o dinheiro), mas usam em lugar bonito... vai ver lá onde eu moro". Percebemos a partir dessa fala uma apropriaçáo a respeito da situação social em que viviam, apropriação essa que já era dramatizada nas peças que montavam na unidade. Entendemos essa reflexão como essencial para o processo de busca da garantia dos direitos sociais por parte desses jovens, sendo as atividades utilizadas na terapia ocupacional, neste contexto, realizadas no sentido de promover o conhecimento, a luta por e apropriação desses direitos.

O Theatro Municipal passou recentemente por uma reforma, que durou de 2008 a 2010. Durante esse tempo, ficou fechado para eventos e visitas, sendo o processo de restauraçáo planejado para manter as características originais do lugar. Custou, segundo informações oficiais do site do governo, 64 milhóes de reais (GOVERNO..., 2015). Os visitantes têm oportunidade de assistir um vídeo no qual o processo de reforma do local foi detalhadamente mostrado, incluindo a descrição dos materiais utilizados, que incluíam "quilos de ouro, prata e bronze, mármores e pedras raras".

Diante da grandeza e riqueza do local, a reação imediata de um jovem foi colocar, em voz alta, o quanto aquela experiência era inimaginável para a sua realidade: "Eu nem sabia que eu podia entrar aqui". É completado por outro adolescente a seu lado, que afirma que já conhecia muito bem a praça onde se localiza o teatro, mas nunca pensou em vê-lo de outra perspectiva: "Eu roubava correntinha aqui fora, nunca imaginei que algum dia eu estaria aqui dentro".

Percebemos que muitos desses jovens conheciam aquele território, porém, na perspectiva de que era "um lugar onde nunca poderiam entrar", porque, nas palavras deles, "tem muito ouro e é muito bonito".

Compreendemos que, apesar de serem moradores de bairros distantes daquele, estes jovens tinham uma grande circulação pela cidade, mas, ao mesmo tempo, sua circulação simplesmente não proporcionava um sentimento de pertencimento àquele território. Entendemos território não apenas no sentido de delimitação geográfica, mas sim como uma construçáo coletiva de identidades (ALMEIDA; OLIVER, 2001). Pensando no que Alarcon et al. (2013, s/p.) nomeiam de dimensão existencial do território, definido como "modo pelo qual o território ganha sentido a partir da história pessoal", entendemos açóes como essa como forma de contextualizar aquele espaço físico como um espaço existencial na vida daqueles meninos, dessa vez no sentido da existência enquanto cidadáo que usufrui, nesse caso, de seus direitos culturais, e não mais como um local no qual se identificam pelo estigma do "adolescente infrator".

Os adolescentes questionaram os valores dos eventos no teatro: "deve ser tudo muito caro, mais de 100 reais!", e foram informados de alguns eventos mais acessíveis à sua realidade econômica, como os espetáculos pelo preço de 1 real aos domingos, as peças com desconto durante o projeto "Teatro para Todos", e sobre a possibilidade de visitarem sem a necessidade de pagamento, precisando para tal de uma articulação com os serviços de assistência social e suas escolas para garantir esse direito. "Um real? Vou trazer minha namorada, minha mãe e minha sogra aqui. Imagina que moral eu trazer todas elas num lugar bonito desse?". Garantiu-se, a partir daí, um dos aspectos da cidadania cultural, o direito de estar informado quanto aos serviços culturais e as possibilidades de dele participar ou usufruir (CHAUI, 1992). Pediram folhetos informativos para levarem consigo e entregarem a seus familiares na visita do final de semana.

O Plano Nacional de Cultura (Lei 12.343 de 2010), em suas diretrizes, estratégias e açóes apresenta a universalização do acesso dos brasileiros à arte e à cultura como uma necessidade:

$\mathrm{O}$ acesso à arte e à cultura, à memória e ao conhecimento é um direito constitucional e condição fundamental para o exercício pleno da cidadania e para a formaçáo da subjetividade e os valores sociais. É necessário, para tanto, ultrapassar o estado de carência e falta de contato com os bens simbólicos e conteúdos culturais que as acentuadas desigualdades socioeconômicas produziram nas cidades brasileira, nos meios rurais e nos demais territórios em que vivem as populações (BRASIL, 2012, p. 189).

Para tal, o Plano Nacional de Cultura apresenta entre as metas traçadas para os 10 anos que seguiam sua estruturação, o aumento em $60 \%$ do número de pessoas que frequentam museu, centro cultural, cinema, espetáculos de teatro, circo dança e música (meta 29) e a necessidade de incluir políticas 
culturais para jovens e crianças em todas as áreas da cultura (meta 47). Entretanto, o estigma e a falta de informaçáo ainda distanciam os jovens pobres e moradores de periferias desse direito. Reforça-se, portanto, a necessidade de mais ações que aproximem os jovens desses espaços, que permitam a quebra do olhar estigmatizante e que possibilitem o acesso à informação, promovendo tanto a fruição quanto a produçáo cultural por parte dessa população.

No retorno, a empolgação por conhecerem de uma forma diferente um mesmo território anteriormente já ocupado, mas ao qual náo se sentiam pertencentes, fez com que esses jovens solicitassem um evento com seus familiares, para apresentarem uma peça e, a partir desta, contar sobre sua visita e convidar os pais para conhecerem o espaço onde estiveram. Realizaram essa peça, contaram aos pais sobre o passeio, fizeram planos para sua saída, que incluíam poder continuar produzindo cultura e conhecendo novos e velhos espaços a partir de outra perspectiva. Liberman (2002, p. 42) reflete sobre o papel das artes e cultura na terapia ocupacional, e concordamos com a autora que afirma que:

[...] as artes proporcionam ao sujeito produçóes passíveis de alguma visibilidade; produçôes que, quando destacadas como objetos de reflexão, podem constituir elemento de construção, articulação e transformação do cotidiano.

\section{Considerações finais}

Entendemos que a cultura, pela visibilidade de suas manifestaçôes e sua possibilidade de atingir grande número de pessoas, espaços, territórios e realidades, é um campo que possibilita as transformaçóes sociais pelo significado de resistência e denúncia que tem para as classes dominadas.

Falar de cultura, nessa perspectiva, é mais do que apenas se referir à cultura institucionalizada ou hierarquizada; é falar de mais do que manifestaçóes artísticas ou estéticas, e mais do que a lógica de consumo e produção; é falar de uma questão de identidade e reconhecimento. Cultura, políticas e açóes culturais são, portanto, temas que atravessam as diferentes áreas de atuação da terapia ocupacional. Para além do eixo norteador das açóes, a cultura pode ser parte de um diálogo intersetorial entre essas diferentes áreas.

Diante da experiência relatada, observamos que, ao promover o acesso aos espaços de produção e consumo de cultura, garantindo o direito à cidadania cultural, estes jovens puderam construir uma nova identidade, saindo do circuito de perpetuação do estigma de ser jovem, pobre e violento, passando a jovem protagonista, criativo e com possibilidades de escolhas para sua circulação pelos territórios geográficos e existenciais, criando assim novas potências de vidas.

\section{Refêrencias}

ALARCON, S. et al. Território, território existencial e cartografia. 2013. (Material Didático do Projeto Caminhos do Cuidado). Disponível em: <http://comunidades. otics.org/caminhos-do-cuidado/tutores-rj-grupo-sonia-maria/acervo/territorio-territorio-existencial-cartografia>. Acesso em: 18 maio 2015.

ALMEIDA, M. C.; OLIVER, F. C. Abordagem comunitárias e territoriais em reabilitação de pessoas com deficiência: fundamentos para a Terapia Ocupacional. In: DE CARLO, M. M. R. O.; BARTALOTTI, C. C. (Org.). Terapia Ocupacional no Brasil: fundamentos e perspectivas. São Paulo: Plexus, 2001. p. 81-98.

BARROS, D. D. Terapia ocupacional social: o caminho se faz ao caminhar. Revista de Terapia Ocupacional da Universidade de São Paulo, São Paulo, v. 15, n. 3, p. 90-97, 2004.

BARROS, D. D.; GHIRARDI, M. I. G.; LOPES, R. E. Terapia ocupacional social. Revista de Terapia Ocupacional da Universidade de São Paulo, São Paulo, v. 13, n. 3, p. 95-103, 2002.

BARROS, D. D.; LOPES, R. E.; GALHEIGO, S. M. Novos espaços, novos sujeitos: a terapia ocupacional no trabalho territorial e comunitário. In: CAVALCANTI, A.; GALVÃO, C. Terapia ocupacional: fundamentação e prática. Rio de janeiro: Guanabara Koogan, 2007a. p. 354-363.

BARROS, D. D.; LOPES, R. E.; GALHEIGO, S. M. Terapia ocupacional social: concepções e perspectivas. In: CAVALCANTI, A., GALVÃO, C. (Org.). Terapia ocupacional: fundamentação e prática. Rio de Janeiro: Guanabara Koogan, 2007b. p. 347-353.

BOAL, A. Estética do oprimido. Rio de Janeiro: Garamond, 2009.

BOAL, A. O arco-íris do desejo: método Boal de teatro e terapia. Rio de Janeiro: Civilização Brasileira, 1990.

BORBA, P. L. O. Protagonismo. In: PARK, M. B.; FERNANDES, R. S.; CARNICEL, A. (Org.). Palavras chaves em educação não formal. Holambra: Editora Setembro; Campinas: Unicamp/CMU, 2007. p. 214-215.

BRASIL. Estatuto da criança e do adolescente. Sáo Paulo: Cortez, 1990

BRASIL. Ministério da Cultura. As metas do Plano Nacional de Cultura. São Paulo: Instituto Via Pública; Brasília: MinC, 2012. 
BRASIL. Secretaria de Direitos Humanos. Levantamento anual dos/as adolescentes em cumprimento de medida socioeducativa - 2012. Brasília, 2013. Disponível em: <http://www.sdh.gov.br/assuntos/criancas-e-adolescentes/pdf/levantamento-sinase-2012>. Acesso em: 27 jul. 2015.

BRASIL. Secretaria Especial dos Direitos Humanos. Conselho Nacional dos Direitos da Criança e do Adolescente. Sistema Nacional de Atendimento Socioeducativo - SINASE. Brasília, 2006.

BRASIL. Sumário Executivo Relatório de Pesquisa responsabilidade e garantias ao adolescente autor de ato infracional: uma proposta de revisão do ECA em seus 18 anos de vigência. Brasília, 2010. (Série pensando o Direito). Disponível em: <http://prvl.org.br/wp-content/uploads/2010/07/Apura\%C3\%A7\%C3\%A3o-do-Ato-Infracional-Atribu\%C3\%ADdo-a-Adolescentes.doc>. Acesso em: 27 jul. 2015.

CHAUI, M. et al. Politica cultural. Porto Alegre: Mercado Aberto/Fundação Wilson Pinheiro, 1985.

CHAUÍ, M. Política cultural, cultura política e patrimônio histórico. In: CUNHA, M. C. P. (Org.). Direito à memória: patrimônio histórico e cidadania em São Paulo. São Paulo: Departamento de Patrimônio Histórico, 1992. p. 37-46.

CONSELHO FEDERAL DE FISIOTERAPIA E TERAPIA OCUPACIONAL - COFFITO. Resolução 366 de 20 de maio de 2009. Dispóe sobre o reconhecimento de Especialidades e de Áreas de Atuação do profissional Terapeuta Ocupacional e dá outras providências. Diário Oficial [da] República Federativa do Brasil, Brasília, DF, 16 jun. 2009a.

CONSELHO FEDERAL DE FISIOTERAPIA E TERAPIA OCUPACIONAL - COFFITO. Resolução 371 de 6 de novembro de 2009. Dispóe sobre a alteração do artigo $1^{\circ}$ da Resolução COFFITO no 366. Diário Oficial [da] República Federativa do Brasil, Brasília, DF, 30 nov. 2009b.

CONSELHO FEDERAL DE FISIOTERAPIA E TERAPIA OCUPACIONAL - COFFITO. Resolução 383 de 22 de dezembro de 2010. Define as competências do Terapeuta Ocupacional nos Contextos Sociais e dá outras providencias. Diário Oficial [da] República Federativa do Brasil, Brasília, DF, 25 nov. 2010.

CONSELHO FEDERAL DE FISIOTERAPIA E TERAPIA OCUPACIONAL - COFFITO. Resolução 406 de 07 de novembro de 2011. Disciplina a Especialidade Profissional Terapia Ocupacional nos Contextos Sociais e dá outras providências. Diário Oficial [da] República Federativa do Brasil, Brasília, DF, 24 de nov. 2011.

COSTA, A. C. G. Tempo de servir: o protagonismo juvenil passo a passo; um guia para o educador. Belo Horizonte: Universidade, 2001.
COSTA, S. L. Terapia Ocupacional Social: dilemas e possibilidades junto a Povos e comunidades tradicionais. Cadernos de Terapia Ocupacional da UFSCar, São Carlos, v. 20, n. 1, p. 43-54, 2012.

FEFFERMAN, M. Vidas arriscadas: o cotidiano dos jovens trabalhadores do tráfico. Petrópolis: Vozes, 2006.

FERNANDES, M. M. A cultural como direito: reflexões acerca da cidadania cultural. Semina: Ciências Sociais e Humanas, Londrina, v. 32, n. 2, p. 171-182, 2011.

GALHEIGO, S. M. O abrigo para crianças e adolescentes: consideraçóes acerca do papel do terapeuta ocupacional. Revista de Terapia Ocupacional da Universidade de São Paulo, São Paulo, v. 14, n. 2, p. 85-94, 2003 a.

GALHEIGO, S. M. O social: idas e vindas de um campo de ação em terapia ocupacional. In: PÁDUA, E.; MAGALHĀES L. (Org.). Terapia Ocupacional: teorias e práticas. Campinas: Papirus, 2003b. p. 29-46.

GOFFMAN, E. Manicômios, prisōes e conventos. São Paulo: Perspectiva, 1990.

GOVERNO DO RIO DE JANEIRO. Theatro Municipal do Rio de Janeiro. Disponível em: <http://www. theatromunicipal.rj.gov.br/index1.html>. Acesso em: 18 maio 2015.

JUSTA, F. M. C.; HOLANDA, I. C. L. C. Teatro com adolescentes em risco social: práticas de promoção da saúde no contexto terapêutico ocupacional. Revista de Terapia Ocupacional da Universidade de São Paulo, São Paulo, v. 23, n. 1, p. 16-23, 2012.

LIBERMAN, F. Trabalho corporal, música, teatro e dança em Terapia Ocupacional: clínica e formação. Cadernos - Centro Universitário São Camilo, São Paulo, v. 3, n. 3, p. 3-43, 2002.

LOPES, R. E. et al. Juventude pobre, violência e cidadania. Saúde \& Sociedade, São Paulo, v. 17, n. 3, p. 63-76, 2008.

LOPES, R. E.; MALFITANO, A. P. S.; BORBA, P. L. $\mathrm{O}$. O processo de criação de vínculo entre adolescentes em situação de rua e operadores sociais: compartilhar confiança e saberes. Quaestio (UNISO), Sorocaba, v. 8, n. 1, p. 121-131, 2006.

MALFITANO, A. P. S. Campos e núcleos de intervenção na terapia ocupacional social. Revista de Terapia Ocupacional da Universidade de São Paulo, São Paulo, v. 16, n. 1, p. 1-8. 2005.

MARTIN, M. F. Cidadania. In: PARK, M. B.; FERNANDES, R. S.; CARNICEL, A. (Org.). Palavras Chaves em educação não formal. Holambra: Editora Setembro; Campinas: Unicamp/CMU, 2007. p. 83-84.

MINAHIM, M. A. (coord). Sumário Executivo Relatório de Pesquisa - Responsabilidade e garantias ao adolescente autor de ato infracional: uma proposta de revisão do 
ECA em seus 18 anos de vigência. Bahia: Universidade Federal da Bahia, 2010. (Série Pensando o Direito).

MINAYO, M. C. S. Violência Social sob a perspectiva da Saúde Pública. Cadernos de Saúde Pública, Rio de Janeiro, v. 10, n. 1, p. 07-18, 1994.

OUTHWAITE, W.; BOTTOMORE, T. (Org.). Dicionário do pensamento social do século XX. Rio de Janeiro: Zahar, 1996.

REIS, T. de A. M. A Terapia Ocupacional Social: análise da produção científica do estado de São Paulo. 2008. 87f. Dissertação (Mestrado em Ciências) - Universidade de São Paulo, São Paulo, 2008.

SANTOS, D. R.; FEDEGER, A. M. O terapeuta ocupacional no processo de ressocialização de adolescentes em conflito com a lei privados de liberdade: transformação através da ocupação. Revista de Terapia Ocupacional da Universidade de São Paulo, São Paulo, v. 19, n. 2, p. 100-107, 2008.

SILVA, E. P. A.; OLIVEIRA, R. M. $O$ adolescente em conflito com a lei e o debate sobre a reduçâo da maiori- dade penal: esclarecimentos necessários. Brasília, 2015. (IPEA - Nota Técnica). Disponível em: <http://www. observatoriodopne.org.br/uploads/reference/file/505/ documento-referencia.pdf>. Acesso em: 27 jul. 2015.

SILVA, E. R. A.; GUERESI, S. Adolescentes em conflito com a lei: situação do atendimento institucional no Brasil. Brasília: IPEA, 2003. Disponível em: <http://www. ipea.gov.br/agencia/images/stories/PDFs/TDs/td_0979. pdf>. Acesso em: 27 jul. 2015.

TAKEITI, B. A. Juventudes, subjetivação e violências: inventando modos de existência no contemporâneo. 2014. 226f. Tese (Doutorado em Psicologia Social) - Pontifícia Universidade Católica de São Paulo, São Paulo, 2014.

WORLD FEDERATION OF OCCUPATIONAL THERAPY - WFOT; ASSOCIAÇAO BRASILEIRA DE TERAPIA OCUPACIONAL - ABRATO; CENTRO DE ESTUDOS DE TERAPIA OCUPACIONAL - CETO. Definições de Terapia Ocupacional. Lins: Faculdades Salesianas de Lins, 2003.

ZALUAR, A. Integração perversa: pobreza e tráfico de drogas. Rio de Janeiro: FGV, 2004.

\section{Notas}

${ }^{1}$ Sobre a regulamentação da Terapia Ocupacional Social, pode-se consultar as seguintes resoluçôes do COFFITO (Conselho Federal de Fisioterapia e Terapia Ocupacional): Resolução 366 de 2009; Resolução 371 de 2009; Resolução 383 de 2010 e Resolução 406 de 2011 (CONSELHO..., 2009a, 2009b, 2010, 2011).

${ }^{2}$ Utilizamos neste texto a definição de Instituição total proposta por Goffman (1990, p. 11): “[...] um local de residência e trabalho onde um grande número de indivíduos com situação semelhante, separados da sociedade mais ampla por considerável período de tempo, levam a vida fechada e formalmente administrada”.

${ }^{3}$ Violência Estrutural pode ser definida, segundo Minayo (1994, p. 8), como "aquela que oferece um marco à violência do comportamento e se aplica tanto às estruturas organizadas e institucionalizadas da família como aos sistemas econômicos, culturais e políticos que conduzem à opressão de grupos, classes, naçóes e indivíduos, aos quais são negadas conquistas da sociedade, tornando-os mais vulneráveis que outros ao sofrimento e à morte. Conforme assinala Boulding (1981, p. 8), essas estruturas influenciam profundamente as práticas de socialização, levando os indivíduos a aceitar ou a infligir sofrimentos, segundo o papel que lhes corresponda, de forma 'naturalizada"'.

${ }^{4}$ Entendemos a omissão do Estado na garantia de direitos sociais básicos como uma das manifestações da violência estrutural. 